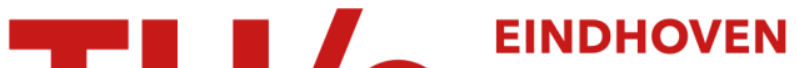 \\ UNIVERSITY OF \\ TECHNOLOGY
}

\section{A monitoring scheme for maintaining the solution to OR- problems}

Citation for published version (APA):

Bertrand, J. W. M. (1983). A monitoring scheme for maintaining the solution to OR-problems. European Journal of Operational Research, 14(3), 228-237. https://doi.org/10.1016/0377-2217(83)90259-X

DOI:

10.1016/0377-2217(83)90259-X

Document status and date:

Published: 01/01/1983

\section{Document Version:}

Publisher's PDF, also known as Version of Record (includes final page, issue and volume numbers)

\section{Please check the document version of this publication:}

- A submitted manuscript is the version of the article upon submission and before peer-review. There can be important differences between the submitted version and the official published version of record. People interested in the research are advised to contact the author for the final version of the publication, or visit the $\mathrm{DOI}$ to the publisher's website.

- The final author version and the galley proof are versions of the publication after peer review.

- The final published version features the final layout of the paper including the volume, issue and page numbers.

Link to publication

\section{General rights}

Copyright and moral rights for the publications made accessible in the public portal are retained by the authors and/or other copyright owners and it is a condition of accessing publications that users recognise and abide by the legal requirements associated with these rights.

- Users may download and print one copy of any publication from the public portal for the purpose of private study or research.

- You may not further distribute the material or use it for any profit-making activity or commercial gain

- You may freely distribute the URL identifying the publication in the public portal.

If the publication is distributed under the terms of Article 25fa of the Dutch Copyright Act, indicated by the "Taverne" license above, please follow below link for the End User Agreement:

www.tue.nl/taverne

Take down policy

If you believe that this document breaches copyright please contact us at:

openaccess@tue.nl

providing details and we will investigate your claim. 


\section{A monitoring scheme for maintaining the solution to OR-problems}

\author{
J.W.M. BERTRAND \\ Department of Industrial Engineering, Eindhoven University of \\ Technology, Eindhoven, Netherlands \\ Received June 1982 \\ Revised October 1982
}

An important problem with the use of OR-solutions for repetitive decision making is how to control the quality of the solution, if the problem to be solved may change with time. Current methods are generally lacking procedures for diagnosing the causes of changes in the quality. In this paper we use concepts borrowed from general control theory to derive a scheme for monitoring the solution. This relates changes in the performance to changes in the quality of the model used, of the decision routine used, of the information used, and in the usage of the solution. It is shown that the existence of a model of the process to be controlled (a design process model), is crucial for designing adequate monitoring procedures. An example of the application of the monitoring scheme to a production control problem in practice is presented and the experience obtained from its use are discussed.

\section{Introduction}

Basically, the stages of an OR project are [1]:

(1) formulating the problem,

(2) constructing the model,

(3) deriving a solution,

(4) testing the model and evaluating the solution, and

(5) implementing and maintaining the solution. Each of these stages involves methodological problems. Much effort has been spent on methods and techniques related to stages (2), (3) and (4). A special branch of Systems Science pays attention to how to formulate the problem (e.g. [7]). Furthermore, a lot has been published on how to implement a solution. However, the problem of how to maintain a solution, or stated otherwise, how to control the quality of a solution, has received much less attention. The statements on this

North-Hoiland

European Journal of Operational Research 14 (1983) 228-237 subject given by Ackoff and Sasieni [1] are still the best material available. They distinguish five types of changes in the system that have to monitored;

(1) changes in the utility of the outcome,

(2) changes in what is controllable,

(3) changes in the constraints over control,

(4) changes in the values of parameters,

(5) changes in the structure of the system.

For all these types of changes they recommand the use of direct checking procedures, to be designed as a part of the solution to the problem. On top of that they recommand controlling the solution as a whole, by the use of periodic tests to determine if the solution's actual performance meets the promise. However, they do not give a method for diagnosing the causes of a changing performance, that is, a systematic procedure to relate a change in performance to changes in the process to be controlled, in the environment of the process, or in the controlling procedures.

In this paper we contribute to the solution of the problem of monitoring the performance and making a diagnosis. We present a method that relates changes in the performance of a controlling system directly to the following four types of changes:

(1) changes in the quality of the model of the controlled process,

(2) changes in the quality of the control procedure,

(3) changes in the quality of the use of the output of the control procedure, and

(4) changes in the quality of the information used by the controller.

The method is based on the use of a specific conceptual framework for defining a problem the first stage in an OR-project - that has been borrowed from General Control Theory (e.g [5]). The framework, and the monitoring procedures derived from the framework, have been successfully used in the design of a production control system in practice. A detailed report of the design process, its methodology, and its results is given in [4]. Here we confine ourselves to presenting the design of the monitoring procedures and giving an 
example taken from the project in practice. But first we present the conceptual framework from which the monitoring procedures are derived.

\section{The conceptual framework}

In general, production control problems can be very complex, involving large numbers of decision variables, state variables and goal variables. In the conceptual framework presented here, it is assumed that a complex production control problem can be decomposed into a number of more or less distinct, simpler control problems. These simpler problems may require coordination, which itself is a distinct control problem. In this paper we assume that the problem has been decomposed as far as required, and we concentrate on a distinct single control problem.

We assume that a control problem can be described as follows:

- a decision function exists;

- the decision function has norms, $N(t)$, for a set of goal variables, $D(t)$;

- the decision function can manipulate a set of controllable variables, $I(t)$;
- the goal variables are influenced by the controllable variables;

- there exists a set of environmental variables, $E(t)$, which influence the goal variables, and which cannot be manipulated by the decision function, but can be observed by the decision function;

- the relationship between the controllable variables and the environmental variables, on the one hand, and the goal variables, on the other hand, is called the process to be controlled. Notice that this definition implies that the nature of the process follows from the definition of the goal variables and the controllable variables - the process is relative to these earlier definitions;

- if the process is dynamic, there exists a set of process state variables, $S(t)$. State variables are defined so that the behaviour of the goal variables during some time interval $(t, t+\mathrm{d} t)$ is completely determined by the state at time $t$ and by the values of the inputs $I(t)$ and $E(t)$, during the time interval $(t, t+\mathrm{d} t)$;

- the decision function may receive information about the behaviour of the goal variables, the state variables and the environmental variables. The decision function may use, either implicitly or explicitly, a model of the environmental process, $M_{e}$,

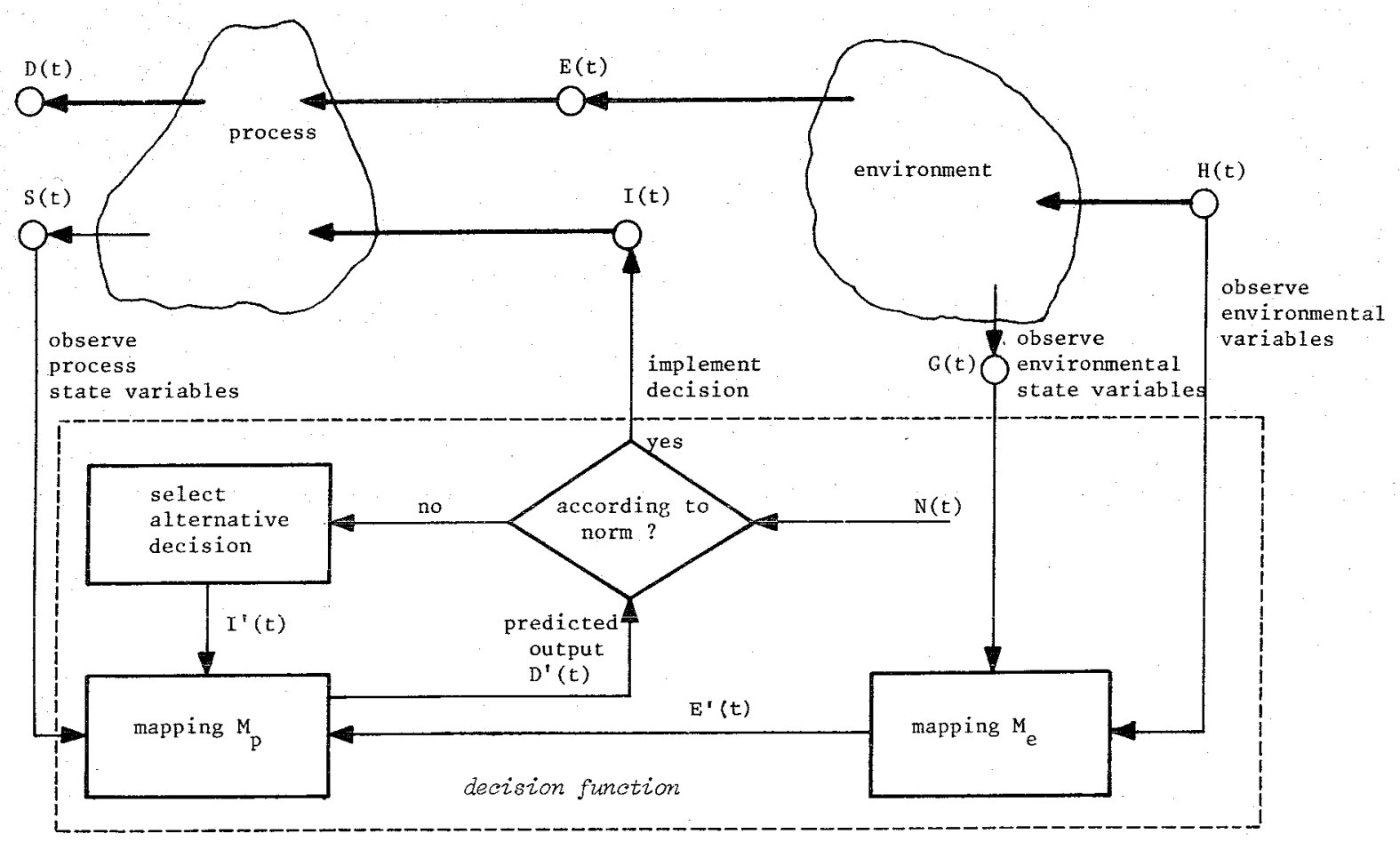

Fig. 1. The conceptual framework of a decision function. 
in order to produce predictions of future values of the environmental variables. Explanatory environmental variables, $H(t)$, which are used as external inputs in the prediction model, may then be defined. If the environmental process is dynamic in nature, then environmental state variables, $G(t)$, can be defined; in that case $M_{e}$ operates on $H(t)$ and $G(t)$. The relationship between $H(t)$ and $G(t)$, on the one hand, and $E(t)$, on the other hand, is called the environmental process;

- the decision function uses, implicitly or explicitly, a model of the controlled process, $M_{p}$, to evaluate possible decisions in the light of the norms, the actual values of the state and goal variables and, possibly, predictions about the environmental variables.

Figure 1 presents the structure of a decision function according to these basic concepts. In the figure $I^{\prime}(t)$ represents possible decisions that are investigated with respect to their expected result, $D^{\prime}(t)$, given the state of the process, $S(t)$, and given the expected values of the environmental variables $E^{\prime}(t)$. Of course, the 'what-if' character of the decision selection routine is used purely for illustration purposes. The decision function could also operate with a simple decision rule acting on $E^{\prime}(t)$ and $S^{\prime}(t)$, in which case the model is implicit - thus the models $M_{e}$ and $M_{p}$ need not be explicitly used in the decision procedure. However, because in our view the models behind the procedure are the essence of the control, their presence is stressed in Fig. 1.

Generally, the models $M_{e}$ and $M_{p}$ will not be perfect: not all variables influencing $D(t)$ or $E(t)$ in reality will be incorporated; their relationships may really be much more complex, the observations of the decision maker with respect to $H(t)$, $S(t)$ and $G(t)$ may contain errors, and finally the decision that follows from the application of the formal decision procedure may not always be completely implemented, for various reasons. In this view on control processes, each of these different sources of uncertainty constitutes a disturbance. The concept of disturbance comprises all factors that affect the predictive quality of the models $M_{p}$ and $M_{e}$. Furthermore, it includes errors in the information available for decision making and deviations that occur in the implementation of decisions. Thus, the nature and the level of disturbance faced by a decision function is determined partly by the quality of the models used.

\section{Models}

From the previous section it will be clear that our view of control system design emphasizes the modelling of the process to be controlled. The relevance of explicit process models for the control of complex processes has frequently been stressed in control literature during the last decades (e.g. [2], [3], [5] and [9]). Tocher [9], discussing the predictability of the results of alternative control actions, states that: "... This can be achieved only by the use of a model of the controlled process. At the heart of every control system there is a model. This may be very rudimentary, its existence may not impinge on the consciousness, but without it control is impossible".

Production control decisions are made by people, and people have mental models of the processes they control. Landeweerd [8] describes the mental process model of a decision maker as the knowledge he has regarding:

- the relationships between changes in inputs to the process and the resulting changes in the outputs of the process;

- the relationships between the undesired outputs and the control actions that should lead to desired outputs.

The mental models are often richer than the formal process models on which, for instance, a computerized routine or a rule of thumb is based (see Fig. 2). Therefore, it is important to allow that the decision makers deviates from the decision advices following from a formal decision procedure. However, the mental model cannot replace the formal process model, as will be shown in the next section. Nevertheless, many situations may occur where no usable formal process model can be found.

To understand this point, consider the position of a designer of a production control system during the design activity. After identification of the controllable variables and the goal variables, the next step to take is to decide how sophisticated the formal decision procedure should be for the proper control of the process. For this decision, the designer may consider various process models have different levels of sophistication and detail. $\mathrm{He}$ will have to evaluate these process models on two aspects:

- quality. This refers to the level of disturbance implied by the use of a process model, which is 


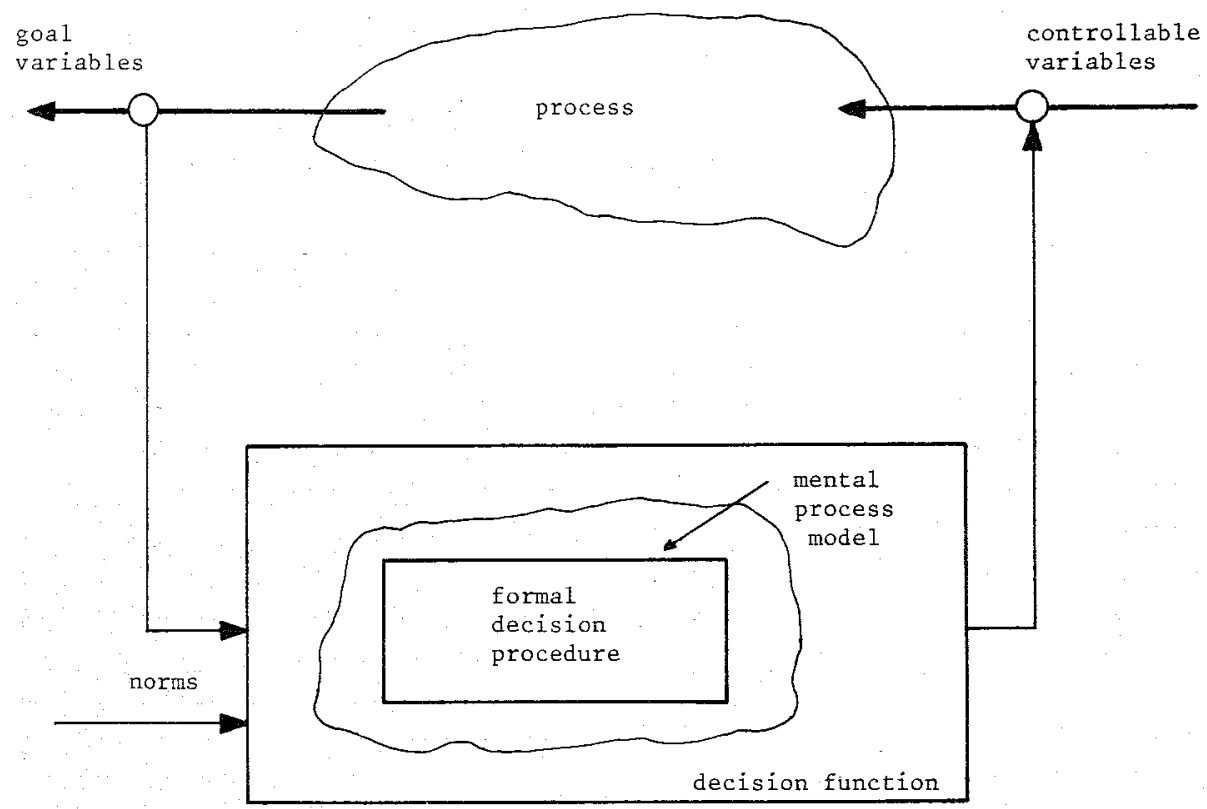

Fig. 2. Symbolic representation of the mental model and the formal decision procedure used in the decision-making process.

closely related to the question of the control performance that can be obtained by using the process model;

- costs. This refers to the organizational effort required for the development and operational use of a decision procedure derived from this process model.

The performance to be obtained should, of course, justify the efforts. The results of this evaluation process may be that no process model can be found with sufficient predictive quality to justify the design, the maintenance and the use of a formal decision procedure. In that case the best thing to do is to consider the design of an information system which presents information about the relevant environmental and state variables to the decision maker. The decision maker uses his mental model of the process to make adequate decisions based on this formal information and perhaps on additional informal information. This does not mean that in such a situation the conceptual framework presented in Section 2 is of no use. For even the design of an information system that only reports on state variables, assumes that these variables have been identified; the production control problem here also has to be modelled in terms of the basic concepts.

\section{Monitoring}

Suppose that the designer has selected a particular process model, which we shall call the design process model, and that he has derived a formal decision procedure from this model. The process to be controlled may change with time. Therefore, the quality of the designed control system may deteriorate with time and it is necessary to monitor this quality continuously to determine whether adaptation of the control system is necessary; if so, diagnosis and redesign activities have to be initiated.

Redesign requires a new organizational project, which does not belong to the normal productioncontrol activities. Determining the need for control adaptation, however, is a different matter: here it is desirable to have a permanent organizational function within the production control, and information systems that perform the monitoring and diagnosis task.

Deterioration of the control performance may have various causes. In the first place the quality of the design process model may deteriorate. We shall call this a model problem.

Secondly, the formal decision procedure may contain errors relative to the design process model (e.g., mistakes have been made in the derivation of 
the required formal decision procedure from the design process model and the control norm) - we will call this a decision procedure problem.

Thirdly, according to our conceptual framework, deterioration of the control performance can also be due to an increase in errors in the information channels - we will call this an information problem. The fourth reason for deteriorating performance can be found in an increased difference between the advised control actions following from the formal decision procedure and the actual decisions. We call this a command problem.

Finally, the control performance may also deteriorate because of large environmental disturbances that unbalance the system so that the available means of control do not suffice: generally, a control system is designed so that it will function well for a specific range of values for the environmental variables. We will call this an environmental problem.

The monitoring system should be able to determine which of these factors causes a change to occur in the control performance. These five causes of performance deterioration will now be discussed in detail.

The design process model has only been accepted as an adequate model after favourable results were obtained in the implementation phase. The level of disturbance implied by the use of this model has been estimated during implementation. Thus we have available:

- an estimate of the performance which can (and should) be obtained by using the formal decision procedure (the decision quality);

- an estimate of the allowed level of disturbance implied by the model (model quality).
If a design process model is used, direct monitoring of the model quality is possible. The monitoring system can supply the model with the actual decisions, the actual behaviour of the environmental variables and the actual values of the state variables, and can compare the results from the process model with the actual behaviour of the goal variables. The model remains adequate as long as the error in the results from the model does not exceed the allowed level of disturbance (model quality) determined in the implementation. Figure 3 illustrates this procedure. Significant changes in the model quality should lead to diagnosis of the causes; after the causes have been found, adaptation of the design process model should be considered. Thus this monitoring procedure constitutes a feedback loop that maintains the quality of the design process model relative to the reality it represents.

The second cause of deteriorating control performance is the occurrence of a decision procedure problem. This means that if the results of the formal decision procedure, based on the correct information regarding the decision situation, are implemented, they no longer produce values of the goal variables that lie within the allowed range. Such a situation may occur if the formal decision procedure is a simplification or a modification of the procedure that, given the specified problem, would follow from the design process model. A simplification may be used if the correct procedure was too difficult to handle, too costly or too time-consuming. Moreover, a simplified procedure will be used if the design process model is so complex that the correct procedure is very difficult to establish, if it can be established at all. A

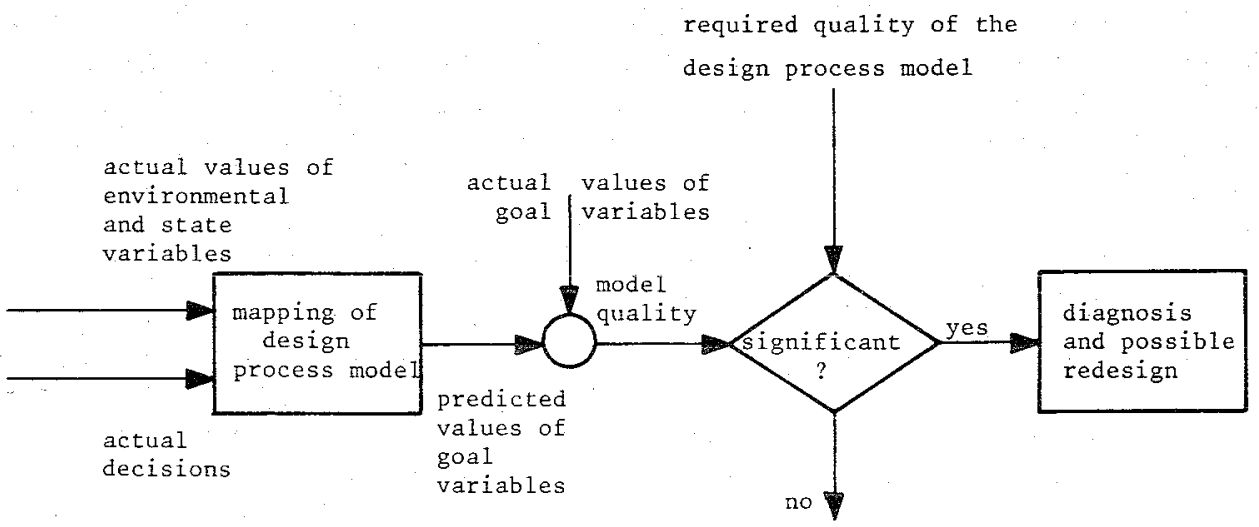

Fig. 3. Scheme of monitoring activities for the quality of the design process model. 
modification is also used if the procedure must be adapted to organizational circumstances which are not incorporated in the design process model. In all these situations the quality of the formal decision procedure should be monitored separately. If, however, the formal decision procedure used follows straightforwardly from the design process model, then monitoring the formal decision procedure is not necessary.

Now suppose that the design process model is sufficiently valid, and that the formal decision procedure needs monitoring. Then the existence of a decision procedure problem can be established by feeding the design process model with:

- the values of the environmental and state variables as perceived by the decision maker, and

- the decisions which, for these values, follow from the former decision procedure.

This yields predictions of the values of the goal variables. If the quality of the design process model is acceptable, comparison of the predicted values of the goal variables with the norms leads to deviations that should be within specified ranges. If not, a formal decision procedure problem may exist. Figure 4 illustrates this procedure. By monitoring the quality of the formal decision procedure after each decision, serious errors in the decision procedure can be identified early, which may result in timely and adequate adaptations. Thus, this monitoring process creates a second feedback-loop that maintains the quality of the decision procedure, relative to the design process model. Because this monitoring process can be performed off-line to the decision process, detailed and time consum- ing calculations are no problem since there is no severe time presure on obtaining the results.

Thirdly and fourthly, the quality of the information and command channels should be monitored. In principle, this can simply be done by. direct comparison. However, we may not expect that these measurements will always be instantaneously available at a detailed level. For instance, the quality of information is often measured by means of time-lagged sampling procedures (e.g. cycle counting of inventories).

The monitoring procedures are derived from the conceptual framework presented in Section 2. The concepts in the framework are strongly interrelated. This creates specific relationships between the various monitoring procedures. Figure 5 shows how these monitoring procedures interrelate and how they are related to the control performance measurement. This is the basic monitoring scheme if a design process model is used.

Finally, the condition of the environment should be monitored. This requires that during the design process, the environmental operating conditions for each decision procedure should have been formally specified, so that adequate monitoring procedures can be designed.

\subsection{No design process model is used}

Now consider the situation where no design process model is available and where no formal decision procedure (not even in the form of a simple heuristic procedure) is used by the decision maker. In that case we may assume that the deci-

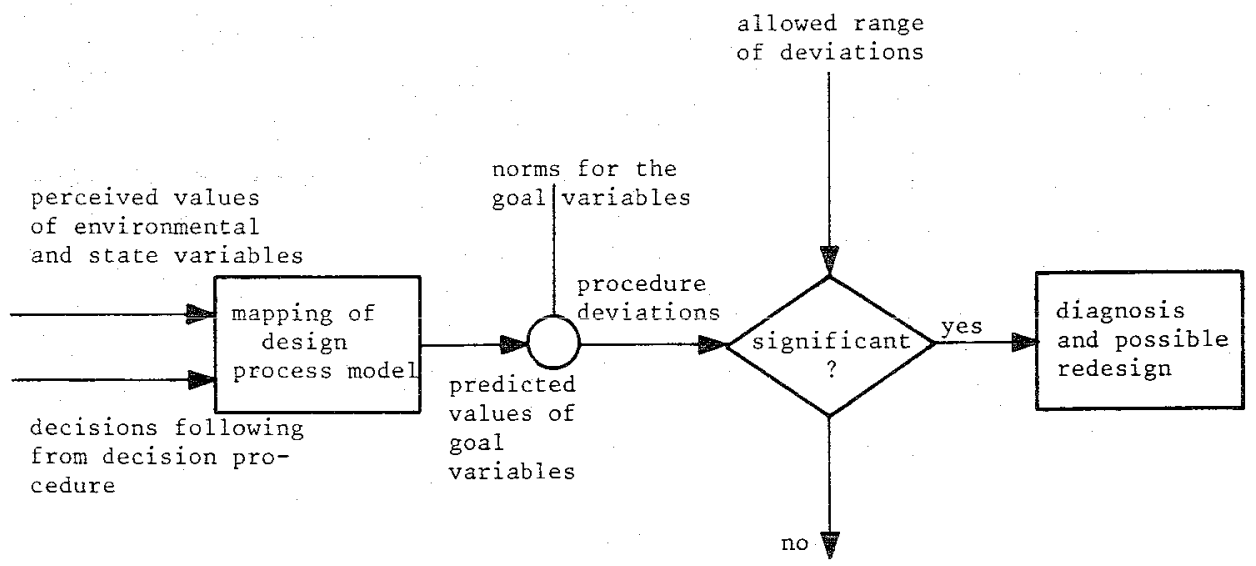

Fig. 4. Scheme of monitoring activities for the quality of the decision procedure. 


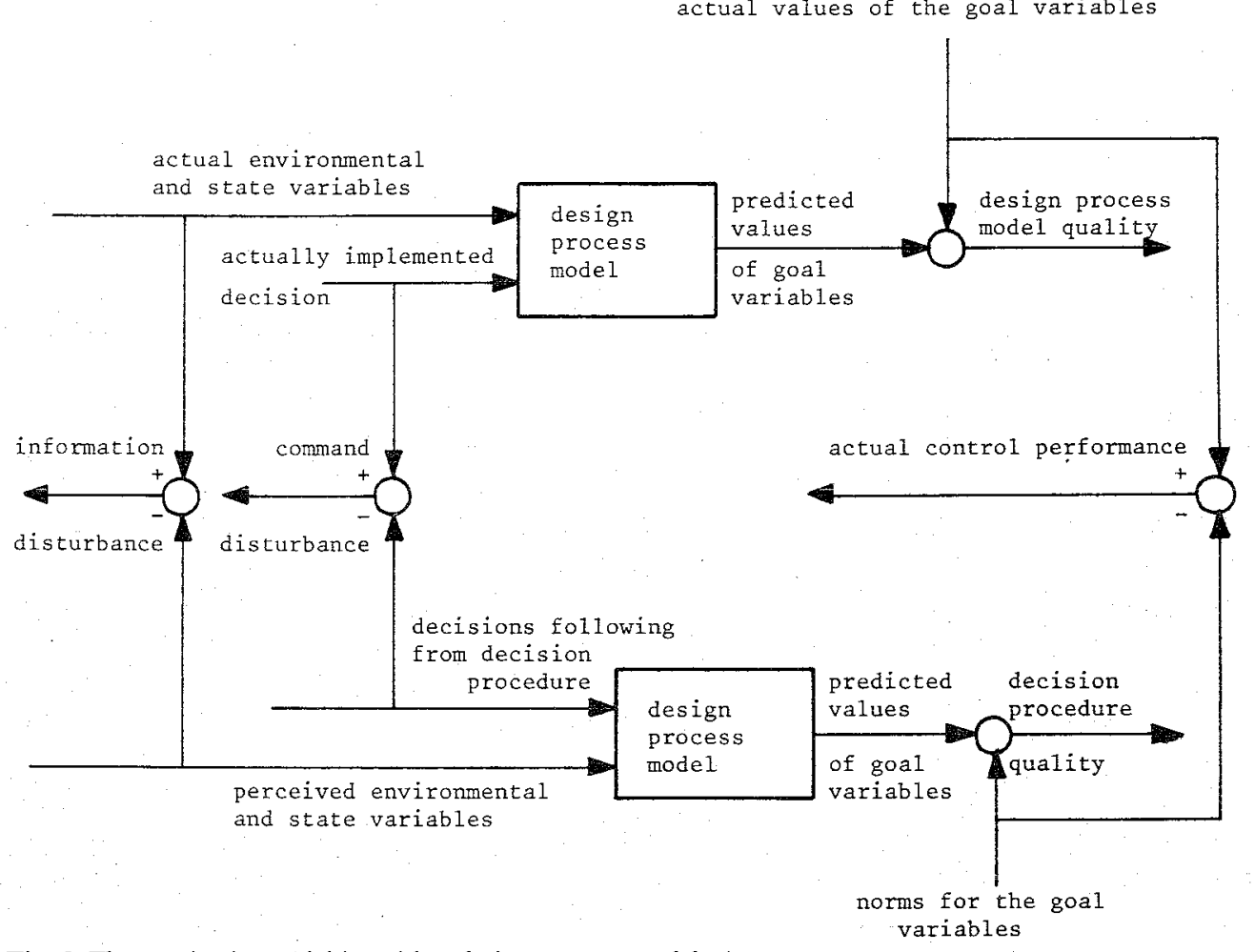

Fig. 5. The monitoring activities with a design process model.

sion maker has internalized a process model (the mental model) by means of learning and training during the implementation phase. Here too, at the end of the implementation phase, we will have an estimate of the control performance of the system, the formal part of which now consists of an information system only. We will, however, have no estimate of the level of disturbance implied by the model; the quality of the mental model can only be monitored indirectly via the performance which results from its use. Moreover, it is not possible to separate changes in model quality from changes in command disturbance or from changes in the quality of the informal decision procedure. Therefore, no direct measurement of model quality, procedure quality and command quality is possible. In this situation, diagnosis of the causes of deteriorating performance is very difficult. However, to support the diagnosis activity to some extent, one could identify crucial variables, that is, variables that may be expected to act as disturbances relative to the mental model, and monitor these variables. But even then, a clear distinc- tion between the various sources of disturbance cannot be made.

An intermediate situation occurs when the decision maker uses a heuristic decision procedure, not derived from a design process model but selected on the basis of theoretical or practical evidence regarding its proper functioning in a wide variety of circumstances. A good example of such a procedure would be the use of the priority rule: "smallest remaining slack per operation" in a dynamic sequencing situation, where a small variance of the job. lateness is important. In such a situation it is possible to monitor also the command disturbances, by comparing the actual behaviour of the controlled variables with the outcome of the formal decision procedure applied in that situation. However, direct monitoring of the quality of the formal decision procedure is still not possible, because this requires that a design process model is available (see Fig. 4).

From the above, it follows that explicit design process models are very important for the control adaptation activity. If such models are not availa- 
ble, then either the diagnosis may become a difficult and tedious activity, or potential disturbance variables have to be identified and monitored, which is possible with command disturbances and with errors in the decision procedure.

In conclusion, if it is decided in the design process to provide the decision maker only with the information he initially demanded or to use a rule-of-thumb type heuristic, then problems are created with respect to the design of an adequate monitoring and control adaptation procedure.

\section{An application}

Monitoring procedures have been designed and used for the decision procedures used by five different decision functions of a production control system in practice. Figure 6 shows the control structure of the system, i.e., the various decision functions, their relationships and the coordination function. As an example we will present in broad lines the monitoring procedure designed for one of these decision functions, the job release decision

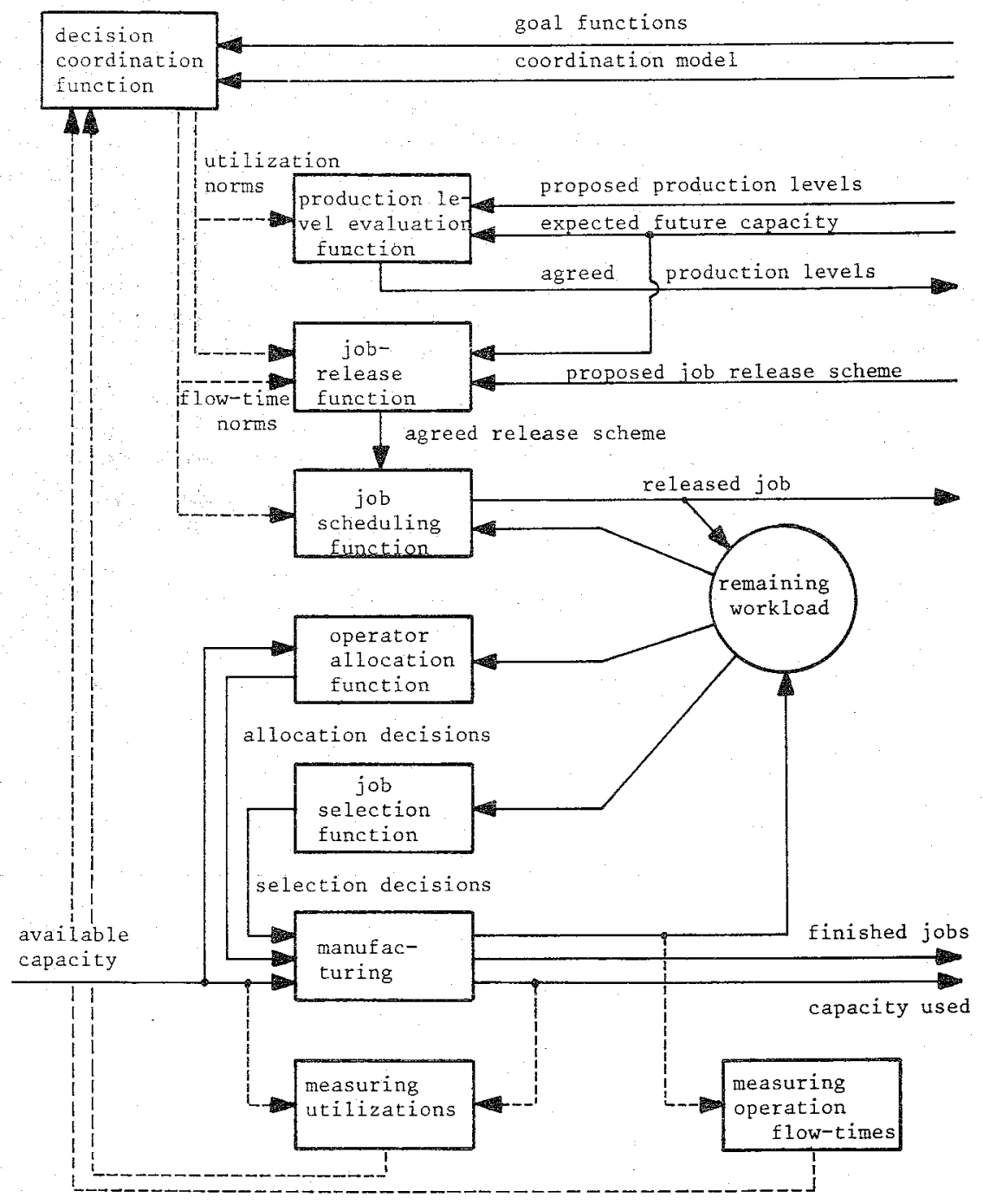

Fig. 6. The structure of a production control system designed in practice. 
function. A detailed account of all monitoring procedures is given in [4]. The goal of the job release decision function was to control the workload in the shop according to a specified norm. The decision function controls the workload on a period base, by determining the number of jobs to be released to the shop during the next period. The workload in the shop is measured per capacity type, by the remaining hours of capacity required by the jobs in the shop. The design process model relates the state of the workload at some point in time, $t$, to the state at time $t-\tau$, the production during $(t-\tau, t)$, and the amount of capacity required by the released jobs during ( $t-$ $\tau, t)$. The model takes some interaction effects between capacity types and some specific queueing effects on the production during $(t-\tau, t)$ into account. The decision procedure is derived from this design process model. However, a number of organizational circumstances had also to be taken into account, leading to a decision procedure that was not a straightforward application of the design process model. Therefore, monitoring of the formal decision procedure was also required. The complete monitoring scheme for the batch release function is shown in Fig. 7.

For all decision functions of the production control systems, using the monitoring procedures yielded valuable information, that was sometimes even used to improve the models and the decision procedures already in the implementation stage. However, the monitoring information also turned out to be useful for other purposes. In his part of the design project, Wortmann [4, pp. 388-389] found that monitoring information was extremely useful for the training of new decision makers and for responsibility accounting. With respect to these topics he reports the following.

Training. A clear distinction between information disturbance, command disturbance, quality of the design process model, quality of the formal decision procedure, and finally, control performance is a powerful means for providing new decision makers with a proper internal model of the process to be controlled and the tools available for control. Real recent figures of this kind focus the discussion immediately on actual control problems. New decision makers are eager to become

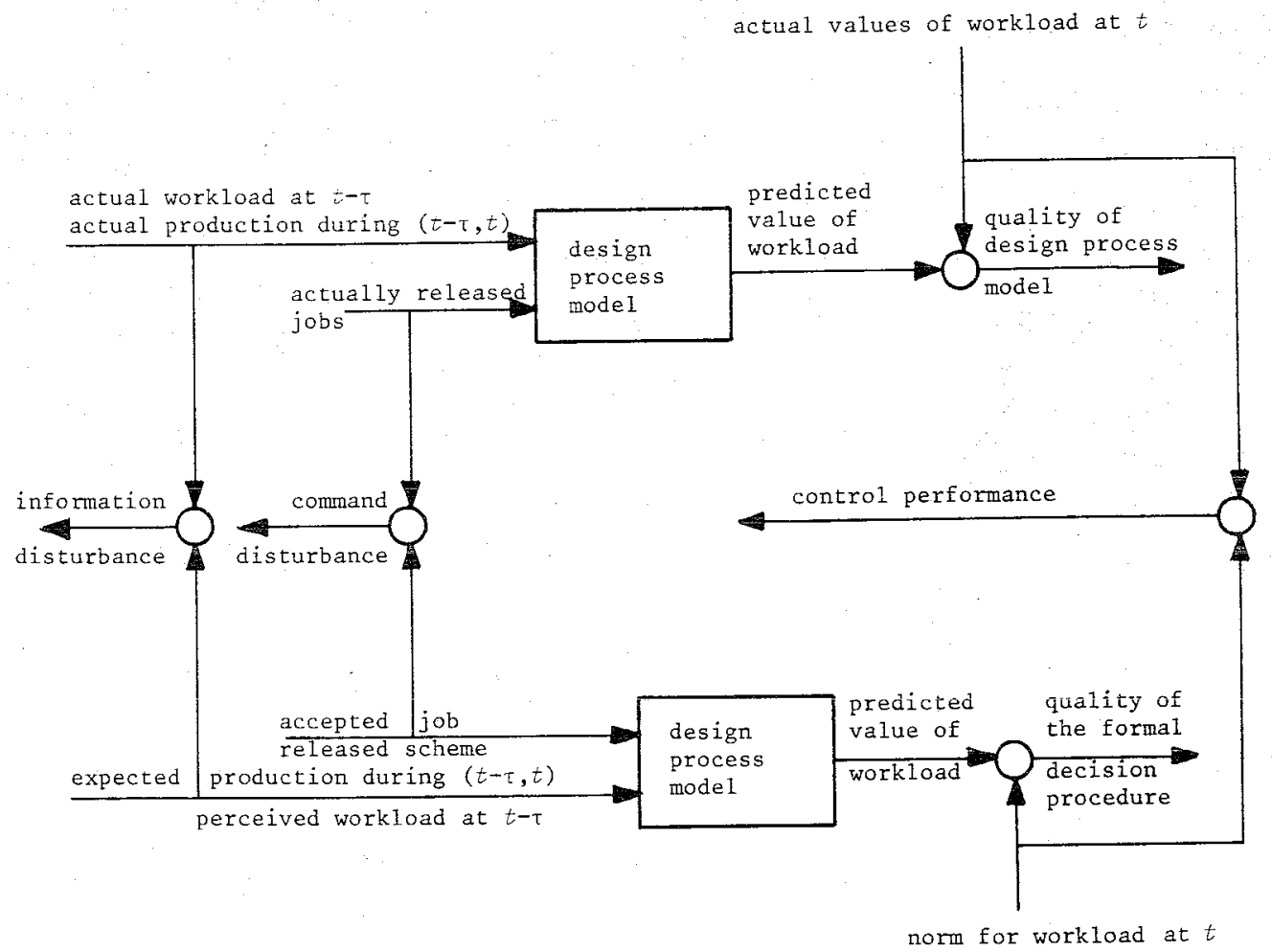

Fig. 7. The monitoring scheme for the job release function. 
acquainted in this way with the design process model, with the formal decision procedure and with the Decision Support System.

Responsibility accounting. Delegation of decision making means that management not only assigns to subordinate executives the decisions on controllable variables, but also the responsibility for local goal variables. If the control problem is well structured, the relationships between controllable variables and local goal variables is simple and clear. Now management cannot exert control over delegated decisions if only the actual values of the goal variables are measured. Firstly, successive values of the goal variables, should be compared with the successive norm values. If the norms change with time, the actual values usually lag behind. Secondly, the actual values of the goal variables should be explained from the actual values of the state variables, the actual values of the environmental variables and the actual values of the controllable variables, by means of the design process model. If this explanation reveals substantial differences, the quality of the design process model is to be blamed. Furthermore, actual values of environmental variables can be compared with predicted values - large deviations indicate that efforts should be directed toward improved forecasting. Finally, the subordinate executives render account of the actual values of the controllable variables. If these actual values differ substantially from the advisory values of the formal decision procedure, management may call for an account of the actual decision-making behaviour.

In this way, the ongoing process of subordinate decision making becomes really transparent for management. This is a substantial improvement as compared with the situations where management is informed only by the actual values of the goal variables, that result as the intertwined product of information disturbances, command disturbances, model quality and time-varying norms.

\section{Conclusions}

We have presented an approach to the problem of controlling the solution of a control problem, derived from a conceptual framework for defining the control problem borrowed from General Control Theory. The approach leads to a monitoring scheme that makes it possible to determine directly the cause of a change in performance (the diagnosis process) and the relate these causes to the change in performance. Application of the monitoring scheme has shown its useability and has revealed two additional advantages of using this scheme. The advantages are an improvement in the possibility of training new decision makers and an increased possibility for responsibility accounting. Of course, more applications of the monitoring scheme in different situations are required to test its useability, but first experiences seem to be encouraging.

\section{References}

[1] R.L. Ackoff and M.W. Sasieni, Fundamentals of Operations Research (Wiley, New York, 1968).

[2] W.R. Ashby, Introduction to Cybernetics (Methuen, London, 1956).

[3] S. Beer, Decision and Control (Wiley, New York, 1966).

[4] J.W.M. Bertrand and J.C. Wortmann, Production Control and Information Systems for Component-Manufacturing Shops (Elsevier Science Pub. Co., Amsterdam, 1981).

[5] R.C. Conant and W.R. Ashby, Every good regulator of a system must be a model of that system, Internat. J. Systems Sci. 1. (1970) 89-97.

[6] O.I. Elgerd, Control Systems Theory (McGraw-Hill, New York, 1967).

[7] W.J.M. Kickert and J.C. van Gigch, A metasystem approach to organizational decision making, Management Sci. 25 (1979) 1217-1231.

[8] J.A. Landeweerd, Internal representation of a process by operator trainees, Ph.D. Thesis, University of Technology, Eindhoven (1978) (in Dutch).

[9] K.D. Tocher, Control, Operational Res. Quart. 21 (1970) 159-180. 